\title{
A FORMAÇÃO INICIAL EM EDUCAÇÃO FÍSICA E AS MAIS RECENTES RESOLUÇÕES DO CONSELHO NACIONAL DE EDUCAÇÃO (CNE): PROBLEMATIZAÇÕES
}

Luiz Felipe Alcantara Hecktheuer Lucas Costa Linck

RESUMO: Este artigo apresenta implicações produzidas diacronicamente, no presente, sobre resultados de uma investigação desenvolvida entre os anos 2016 e 2018, que se dedicou à díade formação inicial em Educação Física/ atuação profissional. Tais implicações resultam da colocação dos resultados da investigação à luz de resoluções mais recentes do Conselho Nacional de Educação (CNE/CES n ${ }^{\circ}$ 6/2018 e CNE/CP n 2/2019). Ao apresentar os principais resultados da referida investigação é inventariado o modo como foram produzidos, logo adiante, estes são tratados considerando as resoluções destacadas. Como principal implicação resultante está destacado a oportunidade de oferta integrada da licenciatura e do bacharelado no mesmo curso de formação inicial em Educação Física, a partir da publicação da resolução CNE/CES nº 6/2018.

PALAVRAS-CHAVE: Formação Inicial. Educação Física. Diretrizes Curriculares Nacionais. Atuação

\section{INTRODUÇÃo}

Formação inicial implicada com a atuação profissional na área da Educação Física, no nível superior - eis uma díade inseparável, polêmica e problemática. Eis também o tema ao qual se dedica este artigo. Tomando de empréstimo problemas produzidos em uma investigação ${ }^{1}$ desenvolvida entre os anos 2016 e 2018, período no qual tínhamos vigente a recente Resolução do Conselho Nacional de Educação (CNE)/Conselho Pleno (CP) $\mathrm{N}^{\circ} 2$, de $1^{\circ}$ de Julho de 2015, que tratava das diretrizes curriculares para a formação em nível superior para os cursos de licenciatura, colocamos estes mesmos problemas à luz de duas Resoluções publicadas após a finalização da investigação: Resolução do CNE/Câmara de Educação Superior (CES) N $^{\circ} 6$ de 18 de Dezembro de 2018 e Resolução CNE/CP N 2, de 20 de Dezembro de 2019, que por sua vez apontam diretrizes Curriculares Nacionais para os cursos de Educação Física e para a Formação Inicial de Professores para atuação na educação básica, respectivamente. Tal diacronia é válida de ser operada, para nós, pelas implicações que estas últimas resoluções podem impor a citada díade.

Assim, neste artigo, nos dedicamos aos resultados de Laboratórios de Problematização ${ }^{2}$ produzidos em uma pesquisa que se dedicou aos concluintes ${ }^{3}$ ou prováveis formandos de quatro cursos de Educação Física da região sul do Rio Grande do Sul e, sobre estes exercitamos implicações possíveis para nós a luz das últimas resoluções publicadas (2018 e 2019). Logo, este artigo parte de uma díade como tema e opera de modo diacrônico em termos de análise.

\section{O problema, a Referida pesquisa e o caso da região Sul do Rio Grande do Sul}

Para facilitar a compreensão do que propomos, esta seção apresenta a já referida investigação, a partir de seu problema e dos instrumentos escolhidos para a produção de seus resultados — resultados estes, que são logo após tomados como objeto de análise e discussão deste artigo.

1 Trata-se da dissertação de mestrado intitulada "Formação inicial em Educação Física: acadêmicos concluintes e a problematização sobre campos de atuação" apresentada junto ao Programa de Pós-Graduação em Educação (PPGEdu) da Universidade Federal do Rio Grande (FURG).

2 Estratégia de método criada no âmbito da referida investigação visando alcançar os objetivos estabelecidos. Tal laboratório de problematização enquanto estratégia de método é pormenorizada ao longo do texto.

3 Ao longo da investigação, foram tratados como concluintes acadêmicos que teriam a possibilidade de finalizar o curso no ano de 2017. 
A temática escolhida para aquela investigação foi a dos currículos de formação inicial em Educação Física, tema este que é compreendido atualmente como algo cercado por polêmicas, principalmente no que se refere aos possíveis campos de atuação dos egressos. Tais polêmicas e embates se dão principalmente no nível das atribuições do Conselho Nacional de Educação Física (criado pela lei 9.696 de $1^{\circ}$ de Setembro de 1998) e da divisão dos cursos em licenciatura e bacharelado, concretizada pela resolução do CNE/CES de 31 de Março de 2004. Em um período anterior ao ano de 2004, a formação inicial em Educação Física funcionava através da licenciatura plena, modelo de formação unificado no qual os egressos estariam aptos a atuar em qualquer ambiente profissional onde a Educação Física acontecesse.

Em 1998, em virtude da criação do CONFEF e das designações feitas pelo mesmo, dois setores de atuações distintas surgem e se consolidam no país após a divisão dos cursos que ocorrera seis anos mais tarde: o escolar e o não escolar. Segundo tais designações, os espaços que compõem o setor escolar são de atuação do licenciado, e os espaços não escolares são de atuação exclusiva dos bacharéis. Porém, o Conselho Nacional de Educação (CNE) reconhece os espaços não escolares como passíveis de atuação tanto do licenciado quanto do bacharel em Educação Física, visto que a Lei 9.394, de 20 de Dezembro de 1996, determinou o fim das licenciaturas curtas, criadas a partir da Lei 5.692/71, em 1971, num contexto em que se exigia uma formação rápida e generalista aos professores da época. Assim, a partir do ano de 1996, toda e qualquer licenciatura passava a ser considerava plena.

Tomando, inicialmente, a relação entre o currículo de formação inicial e os espaços de atuação profissional em Educação Física como conflituosa, estabelecemos como objetivo central daquela investigação, identificar e problematizar as relações potentes de currículos de formação inicial em Educação Física relacionando-as com a atuação do professor de Educação Física em ambientes não escolares. A noção de problematização ${ }^{4}$ percorreu toda a pesquisa, sendo tal ferramenta operatória tomada de Michel Foucault.

Para responder aos objetivos, e como forma de delimitação geográfica inicial, realizamos um mapeamento dos cursos de Educação Física em funcionamento na região sul do Rio Grande do Sul - Brasil, região que engloba 11 municípios. Neste, foram encontrados 18 cursos em funcionamento em 6 diferentes instituições, em regimes presencias e a distancia (EaD), nas modalidades licenciatura e bacharelado. O próximo passo foi contatar as coordenações dos cursos para solicitação dos Projetos Pedagógicos de Curso (PPC), onde surgiu a segunda delimitação do estudo: a escolha por problematizar apenas os PPC dos cursos (de licenciatura e bacharelado) que contassem com alunos concluíntes no ano de 2017. Posteriormente, de posse de cada PPC, o perfil dos egressos ${ }^{5}$ foi problematizado, dedicando-nos a aquilo que era almejado em termos de egresso de cada curso.

Além do processo de mapeamento e problematização dos PPC, outro instrumento para produção de dados foi utilizado, este, fabricado exclusivamente para responder aos objetivos e problemas propostos na referida investigação: o laboratório de problematização. A terceira delimitação da pesquisa se deu então, decidindo interpelar por meio deste instrumento, apenas

4 Problematização não quer dizer representação de um objeto preexistente, nem tampouco a criação pelo discurso de um objeto que não existe. É o conjunto das práticas discursivas ou não discursivas que faz alguma coisa entrar no jogo do verdadeiro e do falso e o constitui como objeto para o pensamento (seja sob a forma da reflexão moral, do conhecimento científico, da análise política etc.). (FOUCAULT, 2010, p. 242).

5 Nomenclatura usual constante nos projetos pedagógicos dos cursos de graduação em nível superior. Pode dizer respeito, tanto ao profissional que pretende ser formado, quanto aos seus possíveis campos de atuação. 
os acadêmicos concluíntes dos cursos presenciais em funcionamento na região, tendo em vista a facilidade em reunir e acessar os mesmos. Assim, a realização dos laboratórios previstos em um número total de 5 cursos, efetivou-se em 4 ( 2 de licenciatura e 2 de bacharelado), tendo em vista a resposta negativa de um dos cursos quanto a sua realização. Foram realizados então, dois laboratórios na Universidade Federal de Pelotas (UFPel), um laboratório na Universidade Federal do Rio Grande (FURG) e um na Faculdade Anhanguera de Pelotas.

O laboratório buscou produzir dados a partir dos significados concebidos pelos acadêmicos partindo do tema formação inicial em Educação Física e dos campos de atuação. Assim, tomamos como problema central naquele procedimento a seguinte questão: qual a potência da formação inicial em Educação Física em relação à atuação em ambientes não escolares?

O primeiro momento do laboratório consistia em uma breve apresentação sobre a investigação, a temática, os objetivos, e o problema de pesquisa, evitando formulações que pudessem induzir os acadêmicos a produzir determinados significados relacionados a alguma das temáticas que já permeavam a pesquisa, permitindo que ressaltassem aquilo que os tocava diante da relação proposta entre formação inicial em Educação Física e campos de atuação.

Após a apresentação, o segundo momento se estabelecia a partir da proposição de um desafio em que os acadêmicos divididos em grupos deveriam elaborar um banner digital que tratasse da relação entre formação inicial e campos de atuação. Para tanto, foi fornecido um modelo de banner (por meio de um dispositivo Pen Drive) e estipulado o tempo de vinte minutos, em que eles poderiam, se necessário, acessar a internet, com o intuito de buscar algum conteúdo que possibilitasse a ilustração e a solidificação de alguma discussão relacionada ao desafio proposto.

O terceiro e último momento do laboratório de problematização tinha como fundamento a apresentação dos banners produzidos por cada grupo, em um tempo aproximado de cinco minutos, buscando discutir com os demais participantes do laboratório aquilo que estava sendo tratado em sua produção. Na ocasião de apresentação e discussão, foi utilizado um gravador de áudio para realizar a captura das falas dos acadêmicos, as quais foram posteriormente transcritas. Assim, o laboratório foi planejado para ter uma duração total de 45 minutos. Todos os laboratórios realizados deram conta de não extrapolar o tempo planejado.

Neste sentido, a partir daquilo que foi problematizado nos PPC, relacionando com o material oriundo dos banners e discussões realizadas no momento de apresentação, temáticas emergiram, sendo posteriormente agrupadas num processo nomeado por nós inventário de temáticas. Assim, os temas considerados relevantes a aquela investigação foram: necessidade pela busca de conhecimentos externos à universidade; dificuldade de atuação no esporte de rendimento; intersecção entre aquilo que é escolar e não escolar; dificuldade no que se refere aos conhecimentos pedagógico/didático; licenciatura como algo maior do que a atuação escolar; quem é professor e quem não é; disputas de mercado; divisão do curso (licenciatura e bacharelado) e a relação com o CONFEF.

O inventário de temáticas apontou para uma acentuada disputa por campos de atuação a partir de diferentes atribuições legais; para uma incoerência e insatisfação dos acadêmicos em relação aos conhecimentos contidos em cada modalidade de ensino em relação a diferentes espaços de atuação e, para uma confusão acerca de quem pode ou não ser tratado como professor a partir da divisão dos cursos. A relação entre formação inicial em Educação Física e os campos de atuação não escolares mostrou-se potente e múltipla, porém foi identificado que tais relações 
poderiam ser ainda mais potentes, principalmente pela constatação de certa resistência manifestada pelos acadêmicos licenciados no sentido das atribuições restritivas que lhe são feitas em relação a esses ambientes.

\section{RESOluÇões do CNE DESDE 2004: LUZES SOBRE O TEMA}

A partir de uma análise das produções científicas que tocam as atuais divergências de posicionamentos acerca das diretrizes que tangem a formação em Educação Física no país MAIA (2020), demonstrou, dentre outros fatores, a existência da centralidade da Resolução CNE/CES $n^{\circ}$ 07/2004 nas diferentes produções que exercem aproximação com esta temática nos anos pós divisão do curso. Tratar de formação e atuação em Educação Física significa tratar desta divisão?

\footnotetext{
Significa dizer que o grupo crítico às Diretrizes de 2004 enxergou na Minuta uma possibilidade de restituição do prejuízo saldado durante a última década. Em contrapartida o grupo de acato às Diretrizes de 2004 não vislumbrou uma possibilidade de proveito em decorrência da Minuta em questão. A permanência deste desentendimento, ao longo da última década, é também objeto de vislumbre dos temas e subtemas relativos à produção científica. (MAIA, 2020, p.13)
}

A partir de tal constatação visamos delimitar a duração de uma problemática que não se iniciou em 2004, mas que teve na Resolução 07/2004 um marco impactante para a díade formação inicial/atuação profissional. Outras resoluções a sucederam, mas esta tem seu impacto crucial no fato de ter estabelecido a divisão da formação inicial em Educação Física em licenciatura e bacharelado.

Os resultados produzidos através daqueles laboratórios de problematização são, nessa seção, problematizados sob a ótica de três resoluções que estão diretamente ligadas ao problema da formação inicial e atuação profissional em Educação Física no país atualmente e que, desde a Resolução CNE/CES n ${ }^{\circ}$ 07/2004, são consideradas por nós como as mais impactantes. Trata-se, de uma parte, da resolução do $\mathrm{CNE} / \mathrm{CP} \mathrm{N}^{\mathrm{o}} 2$, de $1^{\circ}$ de Julho de 2015, considerada na investigação citada, já que vigente naquela data (2017); de outra parte, da resolução do CNE/CES No 6 de 18 de Dezembro de 2018 e da resolução CNE/CP N 2, de 20 de Dezembro de 2019, sendo que estas duas últimas foram aprovadas e divulgadas em data posterior à finalização dos resultados aqui considerados.

A operação de problematizar diacronicamente e produzir implicações destas novas resoluções com os resultados já produzidos pretende ilustrar esta conflituosa disputa que há décadas se acentua no país em relação à formação inicial em Educação Física, alimentada por distintas atribuições prescritas por diferentes órgãos competentes. A saber, principalmente: CONFEF e CNE.

Dentre as três resoluções aqui abordadas, a primeira delas - $\mathrm{N}^{\mathrm{o}} 2$, é datada de 2015 , na qual, o CNE define as diretrizes curriculares para a formação em nível superior para os cursos de licenciatura, de formação pedagógica para graduados e cursos de segunda licenciatura, sendo assim, profissionais do magistério que virão a atuar exclusivamente na educação básica.

Através da resolução $\mathrm{N}^{\circ} 2$, ficaram definidas os princípios, os fundamentos, a dinâmica formativa e os procedimentos a serem observados na política, na gestão e nos programas e cursos de formação ofertados. De que maneira o currículo dos cursos participantes daquela investigação voltam sua formação para a atuação na Educação Básica? Em que ponto esta resolução atra- 
vessa o problema da formação e atuação em Educação Física? A quem cabe a atuação escolar no âmbito da Educação Física?

\begin{abstract}
As instituições de ensino superior devem conceber a formação inicial e continuada dos profissionais do magistério da educação básica na perspectiva do atendimento às políticas públicas de educação, às Diretrizes Curriculares Nacionais, ao padrão de qualidade e ao Sistema Nacional de Avaliação da Educação Superior (Sinaes), manifestando organicidade entre o seu Plano de Desenvolvimento Institucional (PDI), seu Projeto Pedagógico Institucional (PPI) e seu Projeto Pedagógico de Curso (PPC) como expressão de uma política articulada à educação básica, suas políticas e diretrizes. (BRASIL, 2015, p.3)
\end{abstract}

Ao problematizarmos a relação entre a formação inicial em Educação Física e atuação do professor na educação básica, uma primeira questão que se apresenta para nós versa sobre a divisão dos cursos em licenciatura e bacharelado, mas não a divisão por si só. Tal fragmentação, em termos curriculares, aponta para uma aparente contemplação das necessidades, expressas em forma de conteúdos, compreendidas como fundamentais a cada uma das modalidades de ensino, algo que pode ser constatado a partir de alguns dos resultados produzidos naquela investigação.

Entendemos que parte dos cursos de licenciatura em Educação Física, por exemplo, passaram, após a divisão, a dar um maior enfoque para questões que anteriormente não exerciam tanta importância nos currículos de licenciatura plena. Em relação ao antigo modelo de formação, que também formava professores para atuarem na educação básica do país, a fragmentação demonstra ter transformado a licenciatura em um produto bastante distinto da licenciatura plena, isto, principalmente, por se colocar de maneira mais próxima das questões ligadas à escola enquanto um espaço de atuação permeado por códigos próprios. Teria sido a divisão em certo ponto benéfica à Educação Física escolar em termos de melhor formação e atuação de seus professores?

Os currículos de licenciatura plena em Educação Física pautavam-se, consideravelmente, no modelo tradicional esportivo. $\mathrm{O}$ esporte exercia centralidade nesse modelo de formação. Como um dos resultados disso, a Educação Física escolar, em muitos casos, passava a ser uma reprodução do esporte de rendimento, e os aspectos didáticos e pedagógicos pouco eram tratados em comparação ao que é visto hoje em um curso de licenciatura em Educação Física.

O currículo tradicional e esportivo difundido fortemente nas décadas de $60,70,80$ do século passado, e também, com menor intensidade, mas ainda assim, exercendo sua influência até o final da década seguinte. Estabeleceu laços de proximidade com o espaço de atuação pertencente, hoje, ao bacharelado; devido à concepção de formação estar vinculada a uma prática desportiva. (CONTREIRA, 2014, p. 10).

Por outro lado, em termos de atuação, é de amplo conhecimento o fato de que apenas um profissional licenciado - portanto, professor - poderá aturar na educação básica, esta, que compreende educação infantil, ensino fundamental e ensino médio. Porém, se tratando da escola enquanto instituição esta afirmação torna-se um tanto quanto problemática, pelo menos se tratando do professor de Educação Física. Isso porque cada vez mais bacharéis adentram os muros da escola, em grande parte dos casos exercendo a docência em modalidades esportivas fora do currículo obrigatório. O que temos de problema com isso? 
Mesmo que estes profissionais não estejam atuando na educação básica, acabam inseridos no âmbito da escola, tornando-se atuantes no processo escolar como um todo, processo este, que é permeado por significados únicos, que segundo os resultados produzidos no laboratório, exercem afastamento da formação de um bacharel em Educação Física atualmente. Determinadas colocações oriundas de acadêmicos de um dos cursos de bacharelado participantes da investigação apontaram para uma necessidade - expressa em forma de carência - de conhecimentos tidos por eles como pedagógico/didático, ao mesmo tempo em que se reconheciam enquanto professores.

Mas a gente é professor. A gente tem que trabalhar isso. Acho que mesmo no bacharelado deveriam ter cadeiras voltadas a isso. E outra coisa que a gente colocou ali, faltou um melhor embasamento teórico e prática nessa área, que é a área da didática. (Grupo 1 - Faculdade Anhanguera - Bacharelado).

E outra coisa que a gente viu ali é que falta, mesmo que o bacharelado seja voltado para os treinamentos, teria que ter cadeiras de licenciatura, com didáticas mais ligadas na atuação, do ser professor. [...] Então falta matéria de didática, falta tu aprender como te posicionar com um grupo de pessoas e a gente não tem isso. (Grupo 1 - Faculdade Anhanguera - Bacharelado).

Existe a necessidade deste tipo de conhecimento, tratado por estes acadêmicos como pedagógico/didático na formação de um bacharel em Educação Física? Porque alguns destes identificam-se como professores, visto que apenas os cursos de licenciatura estão aptos a proporcionar tal formação? Estando colocado, desde a gênese da divisão dos cursos, que a limitação do bacharel é, exatamente e somente, acerca da atuação na escola porque os mesmos estão cada vez mais ganhando espaço neste âmbito?

Outra constatação que se torna relevante para melhor ilustrar aquilo que é discutido nessa seção é o fato de que por mais que o termo "não escolar" tenha aparição frequente nas mais variadas publicações que cercam a atual disputa que toca a formação e atuação em Educação Física, dentre os dois currículos de licenciatura participantes o único que se refere ao termo em algum momento dentro de seu PPC é o da FURG. Por que motivo a separação de campos de atuação é um aparente problema apenas para este curso?

No interior dos motivos que possam ser apontados, podemos constatar que o outro curso de licenciatura participante da investigação funciona em uma instituição que oferta as duas modalidades, diferentemente da FURG, que oferta apenas licenciatura, portanto, o não escolar não parece ser problema neste caso, visto que a divisão está bem clara: licenciatura se dedica ao setor escolar e bacharel ao não escolar. Mas será tão simples?

O curso de licenciatura em Educação Física da FURG, por sua vez, volta sua formação para uma atuação de seu egresso em todos os espaços que necessitem da intervenção de um professor de educação física, portanto, é amplamente atravessado, não só pelo termo "não escolar", mas também pelas questões que cercam a atuação em ambientes que não sejam a escola, sendo isto refletido na colocação de alguns acadêmicos, demonstrando assim, ser uma concepção formativa que exerce centralidade no funcionamento do curso, exteriorizando-se também através de parte dos acadêmicos que são tocados por este currículo.

[...] e como o nosso curso a habilitação é a licenciatura, a gente vê também o peso das disciplinas da formação de professores. [...] mostrar que o curso ele tem uma formação mais ampla pra escola, mas existe uma grande intersecção que compreende o ambiente não escolar. (FURG - Licenciatura - GRUPO 3). 
Neste sentido, tratando de uma formação única, como propõe o curso de licenciatura em Educação Física da FURG, a resolução No 6 do CNE, datada de 18 de Dezembro de 2018, ao instituir as diretrizes curriculares nacionais para os cursos de Educação Física, por meio da organização, desenvolvimento e avaliação, estabelece finalidades, princípios e dinâmicas formativas; apontando assim, para um novo modelo de formação inicial em Educação Física.

Nesta nova organização proposta, o acadêmico terá um ingresso único, ou seja, tanto os acadêmicos ingressantes que pretendem cursar licenciatura como aqueles que pretendem cursar bacharelado terão até o quarto semestre do curso uma formação exatamente igual, com conteúdos comuns - denominado Etapa Comum - e, a partir do quinto semestre deverão direcionar sua formação para a licenciatura ou para o bacharelado - denominadas Etapas Específicas. Esta última etapa deverá perdurar até a conclusão do curso, quando os acadêmicos receberão a titulação correspondente a mesma. Em termos de prazos, todos os cursos em funcionamento no país terão até o mês de dezembro de 2020 (dois anos após sua publicação) para implementar tais diretrizes.

\footnotetext{
I - Etapa Comum - Núcleo de estudos da formação geral, identificador da área de Educação Física, a ser desenvolvido em 1.600 (mil e seiscentas) horas referenciais, comum a ambas as formações.

II - Etapa Específica - Formação específica a ser desenvolvida em 1.600 (mil e seiscentas) horas referenciais, na qual os graduandos terão acesso a conhecimentos específicos das opções em bacharelado ou licenciatura.

$\S 1^{\circ}$ No início do $4^{\circ}$ (quarto) semestre, a Instituição de Educação Superior deverá realizar uma consulta oficial, por escrito, a todos os graduandos a respeito da escolha da formação que pretendem seguir na Etapa Específica - bacharelado ou licenciatura - com vistas à obtenção do respectivo diploma, ou, ao final do $4^{\circ}$ (quarto) semestre, definir sua escolha mediante critérios pré-estabelecidos; (BRASIL, 2018, p.2)
}

Quando tal resolução atravessa o problema da divisão do curso, questionamentos se fazem necessários: por qual razão acaba-se por delimitar um bloco comum de conhecimentos entre os cursos de licenciatura e bacharelado, visto que a ideia da divisão dos cursos desde sua gênese aponta para dois blocos de atuação distintos, o escolar e o não escolar? Qual o tamanho da distância entre o novo modelo de formação proposto na referida resolução e o atual, em vigor no país desde 2004? De que maneira a concepção de formação única é compreendida por acadêmicos de cursos de licenciatura e bacharelado participantes da pesquisa?

Faria Júnior, já em 1992, tratou a divisão do curso de Educação Física como algo amplamente permeado por contradições e questionamentos, principalmente em relação aquilo que o autor chama de corpo de conhecimentos, ou seja, basicamente os conhecimentos centrais na composição dos currículos de licenciatura e bacharelado em Educação Física.

\begin{abstract}
Admitindo-se que um corpo de conhecimentos é concernente com idéias, conceitos, crenças básicas e entendimentos, relacionados com um dado objeto de estudo, uma questão fundamental na discussão é: pode um mesmo corpo de conhecimentos fornecer a base para duas profissões distintas? Ou, contraditoriamente, existem dois corpos de conhecimentos, um correspondente ao magistério (licenciatura) em Educação Física e outro ao bacharelado? (FARIA JÚNIOR, 1992, p. 231).
\end{abstract}

Inicialmente, tratando especificamente do laboratório de problematização realizado no curso de licenciatura em Educação Física da FURG, uma singularidade foi encontrada. Um 
dos banners produzidos neste laboratório, pelo grupo de número 3, acabou por apresentar uma concepção bastante distinta em relação aos demais grupos participantes (tanto do mesmo laboratório, quanto daqueles realizados com turmas de outras instituições). Trata-se daquilo que os acadêmicos denominaram de conjunto intersecção, fabricado pelos mesmos a partir de um conjunto de disciplinas que, segundo eles, seriam capazes de produzir significados relacionados à atuação em espaços escolares e não escolares.

Ao elaborarem uma imagem em que divide as disciplinas obrigatórias do curso em escolar e não escolar, e logo após inserir um conjunto entre os dois círculos, denominados por eles como conjunto intersecção, alguns pontos podem ser destacados. Inicialmente, ao indicar um desafio relacionado aos campos de atuação em Educação Física, é percebido que o laboratório de problematização remeteu esses acadêmicos, de uma maneira espontânea, à divisão entre escolar e não escolar, mesmo que esses dois termos não tenham sido citados no momento da proposta de sua realização.

[...] a gente acaba vendo que algumas delas, são, no curso aqui especificamente mais voltadas pra um lado do que pro outro. Além disso, a gente pode ver que, a gente deixou o círculo do escolar maior, do que o não escolar também. (FURG -Licenciatura - GRUPO 3).

A divisão dos campos de atuação em escolar e não escolar pode ser entendida como um discurso potente, porém não deve ser reconhecida como um discurso materializado por esses acadêmicos, e sim reproduzido pelos mesmos muito em virtude de sua naturalização dentro dos ambientes que cercam a formação inicial em Educação Física. Se a proposta deste curso é formar profissionais aptos a atuarem em todos os ambientes possíveis, por que essa divisão continua sendo reproduzida quando tratamos de formação inicial em Educação entre os acadêmicos desse curso?

A partir daquilo que foi apresentado por estes acadêmicos, a intersecção foi concebida como um entrelaçamento, ou uma transposição de elementos comuns entre si, buscando compreender como isso se estabeleceu como uma noção entre eles. O que determinadas disciplinas produziram de significados a ponto de tal noção se materializar? O que levou essas disciplinas a fazerem parte do conjunto intersecção e não outras? Quais conhecimentos são entendidos como facilitadores tanto para atuação escolar quanto para não escolar?

Buscando compreender tais questões e percorrendo o momento de discussão acerca da produção do grupo, é possível identificar que tal entrelaçamento esteve diretamente ligado a uma vontade de desconstruir aquilo que, segundo eles, se estabelece em relação aos campos de atuação do egresso: o curso não oferecer uma formação para a atuação em ambientes não escolares.

Só que eu acho que a questão mais importante disso tudo ai é poder visualizar que quando alguém fala assim: que o curso não oferece uma formação pra trabalhar fora da escola, [...] ai não existe uma formação pra fora da escola, a pessoa não tá levando em conta esse ponto de intersecção entendesse? A pessoa parece não estar levando o que é na verdade o maior ponto. (FURG - Licenciatura - GRUPO 3).

Identificamos também que aquelas disciplinas tratadas como componentes do conjunto intersecção são vistas pelos acadêmicos como capazes de produzir conhecimentos que poderão ser usados em ambos os ambientes de atuação anteriormente tratados. São elas: Fisiologia, Fi- 
losofia, Lutas, Relações de Trabalho, Esportes, Danças, Cinesiologia, Antropologia, Sociologia, Psicologia, Biologia, Libras, Corporeidade, Ginásticas e Anatomia.

Naquele momento, mesmo que ementas das disciplinas não tenham sido analisadas, pudemos perceber que dois subgrupos emergem desse conjunto intersecção: o das disciplinas da área das ciências biológicas e das disciplinas da área das ciências humanas. Assim, no excerto a seguir, pudemos reconhecer a maneira na qual essa alocação de disciplinas foi feita por eles, demonstrando que de alguma maneira o nome da disciplina remetia os acadêmicos à área de atuação em que ela melhor se enquadrava.

$E$, acho que é interessante a gente falar como é que a gente acabou chegando nisso né. Antes da tentativa de tentar tirar uma posição do coletivo, a gente acabou escutando de cada um, o que cada um se citava quando falava em formação inicial em Educação Física e espaço de atuação. A grande maioria acabou direcionando os olhares a essa maneira da gente expor né, de colocar, de certa maneira classificar as coisas, [...] foi algo que depois que a gente falou a gente acabou pensando e tendo dificuldades quando falava. Por exemplo: falava uma matéria e se perguntava: ta e aí, é não escolar? É escolar? (FURG-Licenciatura-GRUPO 3).

O fato de um dos grupos da FURG ter concebido apontamentos para uma unificação da formação e suas possibilidades de atuação, mesmo que de forma bem distinta ao que propõe a da resolução $\mathrm{N}^{\mathrm{o}} 6$ de 2018 - que não existia naquela data —, nos permite identificar que mesmo depois da divisão dos cursos, a formação unificada nunca deixou de ser pauta de discussões, desde o senso comum até as diferentes vertentes que cercam a produção do conhecimento em Educação Física.

Além da ocorrência destes alunos idealizadores do conjunto interseção terem se colocado desta maneira em um laboratório realizado um ano ${ }^{6}$ antes da publicação oficial da resolução que acabou determinando este novo modelo unificado, outros grupos, oriundos de outras instituições e de diferentes modalidades, também expressaram a vontade por uma formação unificada. O que poderia estar colaborando na sustentação de tal aspiração pela unificação dos cursos?

Essa coisa do dividir pra nos é pior, tu tinha que somar e a gente teria que ter essa formação pra escolher depois que área que quer atuar e não ficar essa coisa dividindo (Faculdade Anhanguera - Bacharelado-Grupo 2).

Acaba em uma fragmentação dos alunos que estudam Educação Física. Isso acaba enfraquecendo a área.[...] Então isso acaba enfraquecendo a nossa área. Eu vejo que as pessoas, a maioria delas não consegue enxergar isso. Também acho que esse negócio de ter separado licenciatura e bacharelado foi um retrocesso. Eu acho que é pra ganhar mais dinheiro, não vejo outra explicação. (ESEF- UFPelLicenciatura - Grupo 1).

A vontade por uma formação única, se dá, até certo ponto, a partir de uma insatisfação relacionada aos conhecimentos contemplados por cada curso, sob a ótica de diferentes espaços de atuação, o que acaba por apontar também, mais um dos entrelaçamentos entre a licenciatura e o bacharelado e seus possíveis espaços de atuação. Uma formação unificada seria capaz de dar conta de proporcionar conhecimentos satisfatórios a todos os espaços de atuação? A licenciatura plena em Educação Física, durante o longo período que se manteve em vigor no país, conseguiu dar conta disto?

6 Os quatro laboratórios foram realizados entre Março e Outubro de 2017. 
Eu acho que a gente fica muito no gesto técnico, a gente aprende a jogar, aprende a praticar o esporte, mas é diferente de aprender a ensinar e trabalhar os diferentes objetivos, identificar as limitaçôes tanto de gesto técnico quanto de gesto fisico, identificar talento. Eu tenho dúvida, eu não sei se é os alunos do bacharelado que têm preconceito com essas disciplinas, entre aspas, mais de licenciatura, e ai tem uma dificuldade depois de transferir, de na prática, utilizar esses conceitos de pedagogia. (ESEF-UFPel - Bacharelado-Grupo U).

[...] vou dar bem um exemplo: se a gente fosse ensinar futsal. Eu acho que a gente ia saber como lidar com aqueles alunos, trabalhar com eles. Mas as regras, como chutar, o pé, essas coisas mais técnicas nós ainda não íamos tá aptos a tá trabalhando né. Talvez na escola fosse o suficiente o que a gente tem de conhecimento, mas se fosse uma escolinha de futsal por exemplo, não seria. A gente teria que buscar formação em outros espaços. (FURG - Licenciatura - GRUPO 1).

Os dois exemplos apresentados anteriormente apontam para uma insatisfação que está amplamente atrelada ao processo de divisão do curso e consequente divisão dos campos de atuação (ou pela vontade por divisão destes). Os conhecimentos que foram tratados como insuficientes em relação a determinados campos de atuação pelos acadêmicos de licenciatura vão de encontro aos que os bacharéis entendem como algo que tenha tratamento excessivo dentro de seu curso. $\mathrm{O}$ mesmo pode ser verificado se tratando da carência relatada pelos bacharéis e aquilo que é visto como foco excessivo dentro dos cursos de licenciatura. Que conhecimentos são esses? Por que relacionam esses conhecimentos com determinados campos de atuação e não outros?

Foi possível identificar então, dois pólos: os bacharéis que expressam carência de conhecimentos tidos como pedagógico/didático, e os licenciados que sentem necessidade de uma maior abordagem acerca dos conhecimentos específico/técnico, conhecimentos estes, que na maior parte dos casos estavam relacionados a modalidades esportivas pautadas pelo alto rendimento. Tal polarização é problemática em ambos os lados.

De um lado o problema está na ideia de que os conhecimentos tidos como pedagógico/ didático são carregados de significados relacionados exclusivamente à atuação escolar. As questões que envolvem o planejamento e o desenvolvimento de uma aula/treinamento, assim como o trato com seu público alvo, parecem necessitar de um embasamento que poderá ir além da questão técnica e específica da aula em questão. A necessidade de um saber/agir pedagógico por parte do professor estaria condicionada pelo ambiente em que se dá sua atuação? Não seria isso algo central à atuação de um professor, independentemente de seu ambiente de atuação profissional? Os ambientes não escolares dispensam o saber/agir pedagógico do professor?

Do outro lado, a carência de conhecimentos compreendidos como específico/técnico apresentada por licenciados foi um problema discutido por Betti (1992), que trata a atuação profissional em Educação Física como pautada principalmente no aspecto intelectual e não no físico/motor como grande parte das pessoas acredita. Para ele, ter habilidades relacionadas a determinado gesto técnico, o "saber fazer", não garante o sucesso profissional na área, neste caso, o ensino desse mesmo gesto a outras pessoas.

[...] saber como ensinar movimentos também não é suficiente. É preciso saber por que ensiná-los ou não a uma certa clientela, sob as circunstâncias de um certo contexto, em determinadas fases do processo ensino-aprendizagem. Isso implica decisões de natureza filosófica, sociológica, psicológica e biológica, teoricamente fundamentadas (novamente um processo intelectual). (BETTI, 1992, p. 240). 
No sentido das competências compreendidas como essenciais a um egresso de um curso de formação inicial em Educação Física, incorporamos à problematização aqui apresentada, a resolução proveniente do CNE, datada de 20 de Dezembro de 2019 que define as Diretrizes Curriculares Nacionais para Formação Inicial de Professores para atuação na educação básica, mesma resolução onde é instituída, também, a Base Nacional Comum para formação de professores da Educação Básica (BNC-Formação). Tal resolução estabelece ainda, em consonância com a Base Nacional Comum Curricular (BNCC), uma série de competências gerais docentes necessárias a atuação de um licenciado na educação básica. As competências gerais e as competências específicas compõem a BCN-Formação, sendo dividas em três dimensões fundamentais: a dimensão do conhecimento profissional, a dimensão da prática profissional e a dimensão do engajamento profissional.

Usaremos como recorte, a dimensão que demonstra se conectar com o exercício de problematização aqui proposto através da díade problemática formação inicial/atuação em Educação Física: a dimensão da prática profissional. Mesmo que a resolução trate de apontamentos norteadores na formação do professor para a atuação na educação básica, um questionamento logo emerge: tais competências são exclusivas de um profissional atuante na educação básica, tornando-se descartáveis no sentido de uma atuação em ambientes não escolares, seja ela por licenciados ou bacharéis em Educação Física?

\footnotetext{
$\S 2^{\circ}$ As competências específicas da dimensão da prática profissional compõem-se pelas seguintes ações:

I - planejar as ações de ensino que resultem em efetivas aprendizagens;

II - criar e saber gerir os ambientes de aprendizagem;

III - avaliar o desenvolvimento do educando, a aprendizagem e o ensino; e

IV - conduzir as práticas pedagógicas dos objetos do conhecimento, as competências e as habilidades. (BRASIL, 2019, p.2)
}

Compreendendo que as competências neste caso, se estabelecem, entre outras condições, a partir dos conhecimentos viabilizados durante a formação inicial, torna-se necessário compreender como determinados fundamentos estão dispostos em cada uma das modalidades possíveis na formação inicial em Educação Física.

Assim, com o atual cenário pautado na divisão entre licenciatura e bacharelado, ao mesmo tempo em que a resolução $\mathrm{N}^{\circ} 6 / 18$ determina um bloco de conhecimentos comum aos primeiros quatro semestres dos cursos, outros questionamentos se tornam relevantes: de que modo os cursos operavam em relação a esta aproximação antes mesmo da publicação de tal resolução? Qual a distanciamento entre licenciatura e bacharelado no que se refere ao corpo de conhecimentos e competências pretendidas aos seus egressos?

\begin{abstract}
Admitindo-se que um corpo de conhecimentos é concernente com idéias, conceitos, crenças básicas e entendimentos, relacionados com um dado objeto de estudo, uma questão fundamental na discussão é: pode um mesmo corpo de conhecimentos fornecer a base para duas profissões distintas? Ou, contraditoriamente, existem dois corpos de conhecimentos, um correspondente ao magistério (licenciatura) em Educação Física e outro ao bacharelado? (FARIA JÚNIOR, 1992, p. 231).
\end{abstract}

Neste sentido, a Resolução CNE/CES n ${ }^{\circ}$ 07/2004 aponta em seu artigo $7^{\circ}$ que os conhecimentos específicos da área estão articulados com as dimensões: culturais do movimento 
humano, técnico-instrumental e didático-pedagógica. Assim, entende-se que essas dimensões seriam abordadas pelas duas modalidades de ensino, como apontou, anos mais tare, o Oficio do Ministério da Educação (MEC)/CNE/CES nº 158/2013 ao afirmar que a formação específica deve ser a mesma para a licenciatura e para o bacharelado. Entretanto, o artigo seguinte da Resolução CNE/CES n ${ }^{\circ}$ 07/2004 configura que as unidades de conhecimento de ensino para a formação de professores em Educação Física se dariam através das dimensões biológicas, sociais, culturais, didático-pedagógicas, técnico-instrumentais do movimento humano, diferente daquilo tratado no artigo $7^{\circ}$.

Ao tratar de um cruzamento de duas modalidades distintas de formação inicial, Contreira (2014) operou algumas problematizações que buscaram demonstrar a maneira com que cursos de licenciatura e bacharelado funcionam dentro de uma mesma instituição, colocados em funcionamento a partir de um quadro docente praticamente igual. Foi verificada então, a existência de disciplinas comuns aos dois cursos, porém, a maneira com que são abordadas pode ser considerada problemática em relação ao que é tido como necessário a determinada modalidade de ensino e seus possíveis campos de atuação, quando consideramos as concepções de cada professor e a maneira com o mesmo irá tratar o tema. Assim, tomando como exemplo uma disciplina relacionada a modalidades esportivas, esta deverá ter tratamento igual nos cursos de licenciatura e bacharelado?

Por fim, colamos em destaque, a partir das noções que emergiram durante todo o processo da investigação que culminou neste artigo, o fato de que os conhecimentos elencados pelos grupos durante o laboratório como pedagógico/didático ou específico/técnico, nada mais são do que saberes científicos produzidos no meio acadêmico. Assim, o exercício que nos dedicamos a fazer direciona-se à inexistente comprovação de que tais saberes são, de fato, utilizados no momento da prática profissional na Educação Física. Betti (1996) trata a construção do conhecimento como um aglomerado de diversos fatores:

\footnotetext{
Em função da variabilidade do contexto, os profissionais constróem sua própria visão de conhecimento útil, que Lawson denomina conhecimento de trabalho ou conhecimento operacional. É um tipo de conhecimento tácito, que resulta do processo de socialização no interior da profissão. Um profissional aprende com outros colegas, aprende por tentativa e erro, adequa suas ações às demandas institucionais, às aspirações da comunidade, etc. Neste processo, seleciona e adapta conteúdos e estratégias de ensino aprendidas na sua formação acadêmica, e despreza outros. (BETTI, 1996, p. 12).
}

Os inúmeros ambientes onde a Educação Física acontece tornam a prática profissional nesta área cada vez mais instável, tendo em vista as diferentes realidades socioculturais e comportamentais existentes. Para Betti (1996) isto está longe de se tratar de uma negação à ciência, porém, tampouco se trata de acreditar que a prática profissional se fundamenta única e exclusivamente nestes conhecimentos. Para o mesmo autor, um dos pontos centrais deste distanciamento entre o que se aprende e o que se faz pode ser a diferença de realidades existente entre a universidade e prática profissional, entre pesquisador e professor.

Profissionais não pensam, agem e falam como pesquisadores; profissionais e pesquisadores trabalham em diversas comunidades epistêmicas; pensam e agem de maneira diferente porque tiveram diferentes experiências de socialização, além de serem diferenciadas as exigências das suas carreiras profissionais e as demandas no seu trabalho. Em outras palavras, a clientela e as instituições exigem condutas diferentes - ser professor 
universitário é diferente de ser professor de $1^{\circ}$ grau, ser professor de $1^{\circ}$ grau é diferente de ser técnico de clube, e assim por diante. A própria linguagem da pesquisa e do conhecimento científico - formal e codificada - não é a mesma linguagem da prática profissional - cotidiana e informal. (BETTI, 1996, p. 11).

Consonante com aquilo que foi tratado pelos participantes dos laboratórios acerca das capacidades necessárias a cada profissional e seus possíveis campos de atuação, Betti (1992) já apontava o dilema existente entre especialista e geralista, algo que, segundo o autor, confunde-se facilmente com o dilema bacharel e licenciado, porém não se trata da mesma coisa. O profissional generalista seria, nesse caso, alguém com capacidade de adaptar-se às diferentes demandas do mercado de trabalho, tendo uma formação pautada na solidez teórica. Entretanto, o generalista cria um problema para a Educação Física, visto que passa a dificultar a articulação de um único currículo que possa ser capaz de formar um profissional competente para atuação em uma área tão diversificada.

Em contrapartida, aquilo que é entendido por Betti como especialista também configura um dilema, visto que um possível esvaziamento do conteúdo da Educação Física poderia ocorrer. "Se optarmos pela especialização, que caminho tomar? Um profissional para o esporte, outro para a dança, outro para o lazer/recreação e outro para a Educação Física, como proposto por Mariz de Oliveira (1989)?” (BETTI, 1992, p. 249).

\section{IMPLICAÇÕES POSSÍVEIS}

A divisão da formação inicial em Educação Física no nível superior ratificada pela Resolução CNE/CES n ${ }^{\circ}$ 07/2004, se estabeleceu como resultado de disputas de mercado e, em alguma medida, está relacionada ao aligeiramento da mesma, principalmente quando os cursos passam a ser ofertados na modalidade semi-presencial. Muitos de nós professores da área resistimos a estas investidas que se consubstanciaram significativamente desde a criação do CONFEF e suas posteriores normatizações e nas últimas resoluções do CNE desde 2004.

O destacado impacto que inventariamos nestas linhas finais aponta para a oportunidade que a Resolução CNE/CES n ${ }^{\circ}$ 6/2018 nos oferece de exercitarmos uma integração entre as modalidades inventadas na área da Educação Física - licenciatura e bacharelado, pela resolução de 2004. CONFEF e CNE colocam, de um lado, o desafio e as possibilidades da divisão; de outro, os acadêmicos considerados na investigação em voga neste artigo e militantes de diferentes espectros da área da Educação Física clamam pela unificação da formação inicial.

$\mathrm{Na}$ formação inicial em Educação Física foram atribuídas diferenças entre licenciatura e bacharelado a partir dos âmbitos ou espaços de atuação, diferentemente de outras áreas do conhecimento nas quais a diferenciação se dá pela ênfase na docência ou na pesquisa. Produzida a duradoura disputa na área da EF, a Resolução CNE/CES n 6/2018 nos brinda com a possibilidade de integrarmos partes que alguns de nós nunca desejamos separar: licenciado/bacharel; escolar/não escolar; professor/profissional etc. Nos seus artigos $5^{\circ}$ e $30^{\circ}$, a referida resolução torna possível que a Graduação em Educação Física seja ofertada de modo integrado:

Art. 5 - II - Etapa específica - $\S 3^{\circ} \mathrm{A}$ integração entre as áreas específicas [licenciatura e bacharelado] dependerá de procedimento próprio e da organização curricular institucional de cada IES, sendo vedada a eliminação de temas ou conteúdos relativos a cada uma das áreas específicas indicadas. (BRASIL, 2018, p.2) 
Art. 30 As Instituições de Educação Superior poderão, a critério da Organização do Projeto Pedagógico Curricular do Curso de Educação Física, admitir, em observância do disposto nesta Resolução, a dupla formação dos matriculados em bacharelado e licenciatura. (BRASIL, 2018, p.8)

Considerando os problemas produzidos em laboratórios de problematização tomados por objeto de análise neste artigo, destacamos que a principal consequência de tal integração, qual seja, licenciatura e bacharelado, integrados em uma mesma Graduação em nível superior, é a produção de um egresso com formação docente, independente do espaço que venha a atuar. Tal formação docente havia sido suprimida do currículo do bacharelado desde a divisão imposta desde 2004, ainda que, mesmo considerando a delimitação dos espaços não escolares de atuação de um bacharel, haja sempre oportunidades em que a relação professor/aluno, tão característica da atuação docente, se apresente a este profissional. Em termos sumários, pode-se dizer que esta oportunidade fornecida pela resolução de 2018, viável pela integração prevista no art. 30 de tal resolução, nos permite vislumbrar um movimento em direção à possibilidade de oferta de cursos em que estejamos mais próximos da unificação da formação inicial em EF, algo que para alguns de nós nunca deveria ter se dividido.

\title{
THE INITIAL TRAINING IN PHYSICAL EDUCATION AND THE LATEST RESOLUTIONS OF THE NATIONAL COUNCIL OF EDUCATION (CNE): PROBLEMATIZATIONS
}

\begin{abstract}
This article presents implications produced diacronically, at present, on the results of an investigation developed between the years 2016 and 2018, which was dedicated to the initial training in Physical Education / professional performance. Such implications result from placing the results of the investigation in the light of more recent resolutions of the National Education Council (CNE / CES n ${ }^{\circ} 6 / 2018$ and CNE / CP n 2/2019). When presenting the main results of the referred investigation, the way in which they were produced is inventoried, soon afterwards, these are treated considering the highlighted resolutions. As the main resulting implication, the opportunity to offer an integrated degree and bachelor's degree in the same initial training course in Physical Education is highlighted, following the publication of resolution CNE / CES n ${ }^{\circ} 6 / 2018$.
\end{abstract}

KEYWORDS: Initial Formation. Physical Education. National Curriculum Guidelines. Performance

\section{REFERÊNCIAS}

BETTI, Irene Rangel. Novas perspectivas na formação profissional em Educação Física. Revista Motriz - Volume 2, Número 1, Junho/1996.

BETTI, Mauro. Perspectivas na formação profissional. In: Educação Física \& Esportes: Perspectivas para o século XXI. Campinas, SP: Papirus 1992. - (Coleção Corpo \& Motricidade).

BRASIL. Lei $\mathrm{n}^{\circ}$ 9.696, de 1 de Setembro de 1998. Disponível em: <http://www.planalto.gov.br/ ccivil_03/leis/19696.htm>. Acesso em 29/05/2020.

Ofício $\mathrm{n}^{\mathrm{o}}$. 158, de 21 de junho de 2013. Disponível em: http://portal.mec.gov.br/index. php?option=com_docman \&view=download\&alias=14538-pces158-13-1\&category_slug=novembro2013-pdf\&Itemid=30192. Acesso em: 21/03/2019

Diretrizes Curriculares Nacionais para os cursos de graduação em Educação Física, de 31 de Março de 2004. Disponível em: <http://portal.mec.gov.br/cne/arquivos/pdf/ces0704edfisica.pdf>. Acesso em: 29/25/2020

Lei $\mathrm{n}^{\circ}$ 9.394, de 20 de Dezembro de 1996. Disponível em: <http://www.planalto.gov.br/ ccivil_03/leis/L9394.htm>. Acesso em: 25/04/2020. 
Lei 5.692, de 11 de Agosto de 1971. Disponível em: <http://www.planalto.gov.br/ccivil_03/ leis/L5692.htm>. Acesso em: 12/05/2020

Resolução $\mathrm{N}^{\mathrm{o}} 2$, de $1^{\mathrm{o}}$ de Julho de 2015. Disponível em: http://portal.mec.gov.br/docman/ agosto-2017-pdf/70431-res-cne-cp-002-03072015-pdf/file Acesso em: 28/05/2020

. Resolução No 6, de 18 de Dezembro e 2018. Disponível em: http://www.in.gov.br/materia/-/ asset_publisher/Kujrw0TZC2Mb/content/id/55877795. Acesso em: 14/03/2020

. Resolução No 2, de 20 de Dezembro de 2019. Disponível em: http://portal.mec.gov.br/docman/ dezembro-2019-pdf/135951-rcp002-19/file. Acesso em: 07/03/2020

CONTREIRA, Clairton. As percepções de professores do ensino superior sobre a atual divisão curricular do curso de Educação Física em licenciatura e bacharelado: um estudo de caso. Espaço do currículo, v.7, n.2, p.336-349, Maio a Agosto de 2014.

FARIA JÚNIOR, Alfredo Gomes de. Perspectivas na formação profissional em Educação Física. In: Educação Física \& Esportes: Perspectivas para o século XXI. Campinas, SP: Papirus 1992. - (Coleção Corpo \& Motricidade).

FOUCAULT, Michel. Polêmica, política e problematizações. Ditos \& Escritos V: Ética, sexualidade, política. Rio de Janeiro: Forense Universitária, 2010.

MAIA, Júlio César. A produção científica sobre as Diretrizes Curriculares para a Educação Física (DCNEF): Determinações históricas e implicações para formação e intervenção profissional. Revista Movimento, v.26, p.13. 2020. 